\title{
Language processing abnormalities in adolescents with psychotic-like experiences: An event related potential study
}

\author{
Jennifer Murphy ${ }^{\mathrm{a}, \mathrm{b}}$, Mathieu M. Blanchard ${ }^{\mathrm{b}}$, Caroline Rawdon ${ }^{\mathrm{a}}$, Fergal Kavanagh ${ }^{\mathrm{b}}$, Ian Kelleher ${ }^{\mathrm{b}}$, \\ Mary C. Clarke ${ }^{\mathrm{b}, \mathrm{c}}$, Richard A.P. Roche ${ }^{\mathrm{a}, 1}$, Mary Cannon ${ }^{\mathrm{b}, \mathrm{d}, *, 1}$ \\ a Department of Psychology, National University of Ireland, Maynooth, Co. Kildare, Ireland \\ ${ }^{\mathrm{b}}$ Department of Psychiatry, Royal College of Surgeons in Ireland, Dublin, Ireland \\ c Department of Psychology, Division of Population Health Sciences, Royal College of Surgeons in Ireland, Dublin, Ireland \\ ${ }^{d}$ Department of Psychiatry, Beaumont Hospital, Dublin 9, Ireland
}

\section{A R T I C L E I N F O}

\section{Article history:}

Received 11 March 2011

Received in revised form 9 January 2012

Accepted 17 January 2012

Available online 12 February 2012

\section{Keywords:}

Psychosis

P300

Psychotic-like experiences

Schizophrenia

Language

PLEs

\begin{abstract}
A B S T R A C T
Language impairments are a well established finding in patients with schizophrenia and in individuals at-risk for psychosis. A growing body of research has revealed shared risk factors between individuals with psychotic-like experiences (PLEs) from the general population and patients with schizophrenia. In particular, adolescents with PLEs have been shown to be at an increased risk for later psychosis. However, to date there has been little information published on electrophysiological correlates of language comprehension in this at-risk group. A 64 channel EEG recorded electrical activity while 37 (16 At-Risk; 21 Controls) participants completed the British Picture Vocabulary Scale (BPVS-II) receptive vocabulary task. The P300 component was examined as a function of language comprehension. The at-risk group were impaired behaviourally on receptive language and were characterised by a reduction in P300 amplitude relative to the control group. The results of this study reveal electrophysiological evidence for receptive language deficits in adolescents with PLEs, suggesting that the earliest neurobiological changes underlying psychosis may be apparent in the adolescent period.
\end{abstract}

(c) 2012 Elsevier B.V. All rights reserved.

\section{Introduction}

Language impairments are a central feature of schizophrenia (Condray, 2005; Spironelli et al., 2008). In particular, receptive language deficits are not only present in patients with schizophrenia but also in those at-risk for psychosis such as unaffected family relatives and prodromal individuals (for reviews, see Condray et al., 2002; DeLisi, 2001). Klosterkotter et al. (2001) found that impaired receptive language ability in prodromal individuals was predictive of schizophrenia with a probability of up to $91 \%$ (specificity: $0.85-$ 0.91; false-positive predictions: $1.9 \%-7.5 \%)$. Cannon et al. (2002) demonstrated that receptive language deficits distinguished adolescents who were later diagnosed with schizophreniform disorder from those who were not. Howlin et al. (2000) also reported that ten per cent of a group of children with developmental receptive language disorder had developed schizophrenia in adulthood.

\footnotetext{
* Corresponding author at: Dept Psychiatry, Royal College of Surgeons in Ireland, Education and Research Centre, Beaumont Hospital, Dublin 9, Ireland. Tel.: + 3531 809 3855; fax: + 35318093741.

E-mail addresses: jennifer.b.murphy@alumni.nuim.ie (J. Murphy), marycannon@rcsi.ie (M. Cannon).

${ }^{1}$ Both authors contributed equally to this work.
}

A novel approach to identifying individuals at increased risk for psychosis is the 'symptomatic' at-risk paradigm, which comprises young people with subclinical psychotic symptoms (also known as Psychotic-Like Experiences or PLEs) from the general population (Kelleher and Cannon, 2010; Laurens et al., 2007; 2010). A significant association has been demonstrated between PLEs in adolescence and the onset of a psychotic disorder in adulthood (Poulton et al., 2000; Hanssen et al., 2005; Welham et al., 2009). Blanchard et al. (2010) reported significantly impaired receptive language ability in adolescents with PLEs when compared to a control group. These findings suggest that deficits in processing spoken language may be among the earliest emerging abnormalities in schizophrenia-spectrum disorders.

The P300 event-related potential (ERP), typically elicited with an auditory oddball paradigm, is impaired in patients with schizophrenia (McCarley et al., 1993; Mathalon et al., 2000) and also in first-episode patients (de Wilde et al., 2008), prodromal individuals (Bramon et al., 2008; Ozgurdal et al., 2008) and in those at-risk for psychosis (Frangou et al., 1997; Winterer et al., 2003; Frommann et al., 2008; van Tricht et al., 2010). Although the P300 component is usually thought to reflect memory updating and the allocation of attentional resources, this component can also offer insight into language processing (Connolly and D'Arcy, 2000; Jeon and Polich, 2003). Decreased P300 amplitude was associated with reduced grey matter volume in 
the superior temporal gyrus (STG), an area related to language comprehension, in chronic and first-episode schizophrenia patients and also with STG activation in children genetically at-risk for psychosis (McCarley et al., 1993, 2002; O'Donnell et al., 1999; Rajarethinam et al., 2011).

Previous studies have examined the P300 component in relation to receptive language in healthy individuals and in individuals with language disorders (for review, see Connolly and D'Arcy, 2000). Connolly et al. (1999) adapted the vocabulary subtests of the Wechsler Intelligence Scale for Children-III (WISC-III; Wechsler, 1991) to examine receptive vocabulary with ERPs. A P300 component was present only to words in which the participant knew the meaning of and was absent when words beyond the participant's vocabulary range were presented (Connolly et al., 1999). These findings were also replicated with other standard neuropsychological tests of receptive language (Byrne et al., 1995; Connolly et al., 1995; D'Arcy et al., 2000; Henderson et al., 2011). To our knowledge, no previous studies have examined electrophysiological correlates of receptive language in young people with psychotic symptoms. We hypothesised that in comparison to a control group, adolescents with psychotic-like experiences would exhibit an impaired P300 on a receptive language task.

\section{Method}

\subsection{Participants}

Adolescents aged $10-13$ years old $(M=11.62, S D=.55)$ were recruited from large single- and mixed-sex primary-level schools. Details of the recruitment procedure are provided in Kelleher et al. (2011). Written informed consent was obtained from the parent and the child prior to participation. Following a clinical interview, thirty-seven participants completed EEG testing. Participants were divided into two groups: an "At-Risk" group (7 Male) consisting of sixteen participants reporting psychotic symptoms, and a Control group (12 Male) of twenty-one participants without psychotic symptoms. All participants had normal or corrected-to-normal vision, normal hearing and no previous neurological disorders or brain injuries. No participants were taking any medication at the time of testing. This research was approved by the Ethics Committees of Beaumont Hospital and the National University of Ireland, Maynooth.

\subsection{Assessment of PLEs}

The psychosis section of the Kiddie-Schedule for Affective Disorders and Schizophrenia for School-Aged Children, Present and Lifetime Versions (K-SADS-PL; Kaufman et al., 1996) was employed to investigate the presence of psychotic-like experiences. Hallucinations and delusions were assessed with questions such as "Has there ever been a time you heard voices when you were alone?" and "Has there ever been a time you felt that someone was out to hurt you?" A consensus meeting was held following the interviews to discuss the information contained in the interview on psychotic-like experiences and to decide whether these symptoms could be rated as definite psychotic symptoms.

\subsection{EEG testing}

\subsubsection{ERP task stimuli}

The computerised ERP task was adapted directly from the British Picture Vocabulary Scale-2nd Edition (BPVS-II; Dunn et al., 1997). The task consisted of 96 spoken English words (i.e. nouns, adjectives and verbs) taken from the BPVS-II and were presented through the computer speakers. Each spoken word was accompanied by four pictures, where only one picture matched the word in meaning. The task was presented in eight blocks of increasing difficulty where each block contained 12 trials (see Appendix 1).

\subsubsection{ERP task design}

The task was presented using E-Prime $\odot$ stimulus presentation software. The onset of a trial was indicated by a fixation cross located in the centre of the screen for $500 \mathrm{~ms}$. Following the offset of the fixation cross, four black and white pictures presented in a $2 \times 2$ array appeared on-screen which were subsequently followed by a spoken word (ISI $1000 \mathrm{~ms}$ ). The pictures remained on screen until the participant responded. Each picture contained a coloured dot that corresponded to a coloured button on a RB-834 response box (Cedrus $\odot$ ). The participant's task was to select the picture that matched the spoken word in meaning. Following the response, a blank screen was presented for $1000 \mathrm{~ms}$ to allow for blinking and a fixation cross signalled the onset of a new trial.

\subsection{EEG recording}

EEG data were recorded using silver/silver chloride electrodes (Brain Vision@) at 64 electrode sites positioned according to the extended 10-20 system of electrode placement. Horizontal eye movements (HEOG) were recorded from electrodes positioned at the outer canthus of each eye. Vertical eye movements (VEOG) were recorded from electrodes located above and below the left eye. The reference electrode was placed on the nasion of the nose. Skin was lightly abraded to maintain an impedance level below $10 \mathrm{k} \Omega$. The EEG signal was amplified (Brain Vision@) with a band-pass filter of $0.16-100 \mathrm{~Hz}$ and a gain of 1000. EEG data were digitised at a sampling rate of 500 . The conversion rate was $2000 \mathrm{~Hz}$ per channel and the range was $150 \mathrm{mV}$. Filters were set at a low cut off of $0.53 \mathrm{~Hz}$ and a high cut off of $30 \mathrm{~Hz}$. Recordings were notch filtered offline at $50 \mathrm{~Hz}$. Blinks were averaged off-line and an EOG automatic artefact rejection algorithm was applied to the data (Berg and Scherg, 1991; Ille et al., 2002).

E-prime logged accuracy scores and reaction time in real time for each trial. ERPs were obtained by averaging the EEG around an epoch of $1300 \mathrm{~ms}$ (i.e. $-100 \mathrm{~ms}$ pre-stimulus to $1200 \mathrm{~ms}$ post-stimulus). ERPs were stimulus-locked to the onset of the auditory presentation of the word and were response-binned into correct and incorrect responses to investigate the presence of the P300 at 280-500 ms. Table 1 demonstrates the average number of trials per person that was included in each condition.

\subsection{Statistical analyses}

Participants were compared on demographic variables such as age, sex, and handedness. Mixed factorial ANOVA were carried out on accuracy and reaction time scores. ERP data from the eight blocks of the task were collapsed into two levels of difficulty based on the accuracy scores. The first four blocks were collapsed and defined as an 'Easy' level resulting from high accuracy obtained by all participants and the final four blocks were identified as a 'Difficult' level due to a significant drop in accuracy scores across all participants [t $(36)=$

Table 1

Mean number of trials accepted per person for the averaged ERP waveforms.

\begin{tabular}{|c|c|c|c|}
\hline \multirow[t]{2}{*}{ Condition } & Overall $(\mathrm{N}=37)$ & Controls $(\mathrm{N}=21)$ & At-risk $(\mathrm{N}=16)$ \\
\hline & $\mathrm{M}(\mathrm{SD})$ & $\mathrm{M}(\mathrm{SD})$ & $\mathrm{M}(\mathrm{SD})$ \\
\hline Overall grand avg. & $70.92(13.02)$ & 73.67 (12.49) & $67.31(13.20)$ \\
\hline Easy & $43.62(5.12)$ & $44.19(5.22)$ & $42.88(5.06)$ \\
\hline Difficult & $27.30(11.60)$ & $29.48(11.02)$ & $24.44(12.08)$ \\
\hline Correct overall & $46.24(12.61)$ & $50.57(13.34)$ & $40.56(9.15)$ \\
\hline Correct-easy & $36.00(6.90)$ & $37.81(6.31)$ & $33.63(7.12)$ \\
\hline Correct-difficult & $10.76(7.94)$ & $13.24(8.71)$ & $7.50(5.50)$ \\
\hline Incorrect overall & $23.68(6.95)$ & $24.00(7.25)$ & $23.25(6.75)$ \\
\hline Incorrect-easy & $7.70(4.93)$ & $7.52(5.05)$ & $7.94(4.92)$ \\
\hline Incorrect-difficult & $15.97(5.80)$ & $16.48(5.97)$ & $15.31(5.93)$ \\
\hline
\end{tabular}


10.271, $\mathrm{p}=.000$ ]. From visual inspection of the grand averaged waveforms, a P300 component was evident at frontal (Fz) and central (Cz) electrodes.

Mean amplitude and peak latency data were subjected to analyses which examined differences across Task Difficulty (Easy and
Difficult), Condition (Correct and Incorrect) and Group (Controls, At-Risk). Fig. 1 illustrates the waveforms for each group across Correct and Incorrect responses. For each ANOVA, an alpha value of .05 was used for main and interaction effects. Greenhouse-Geisser correction was reported when the assumption of sphericity was violated.

A

Controls vs. At-Risk

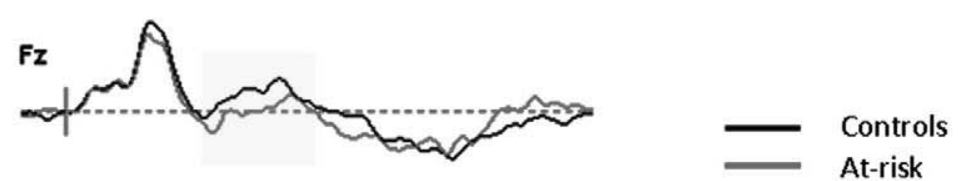

\section{Correct Responses}
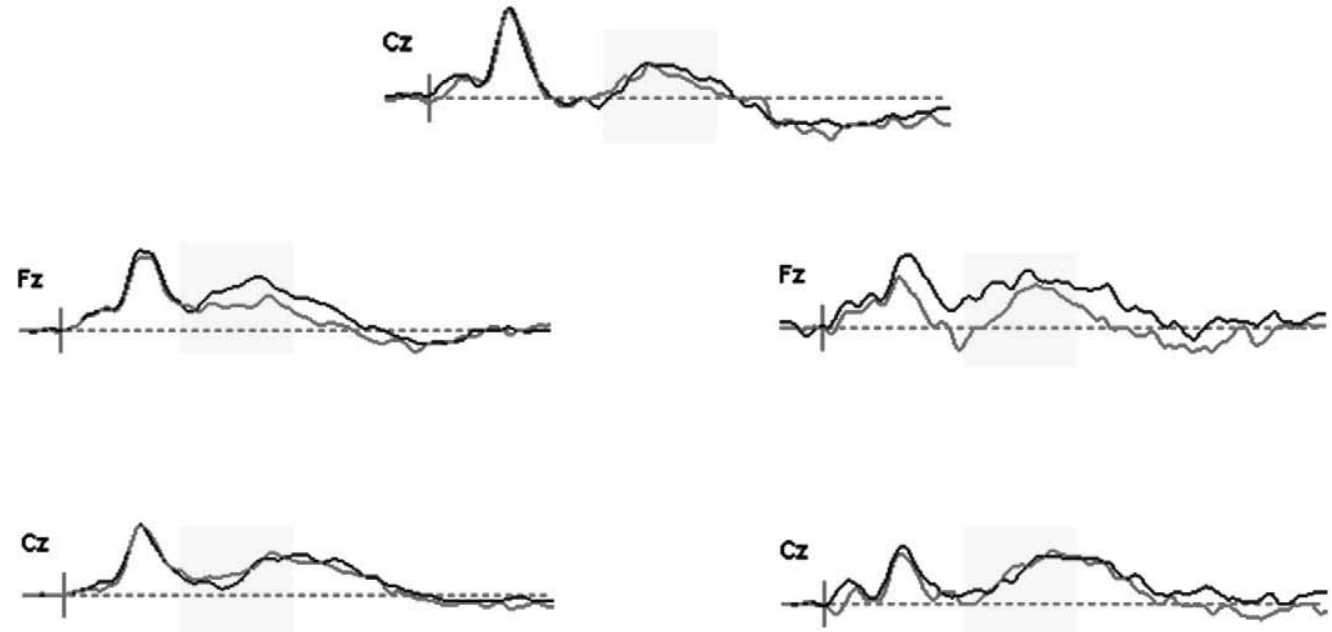

Easy Correct

Difficult Correct

B

\section{Controls vs. At-Risk}

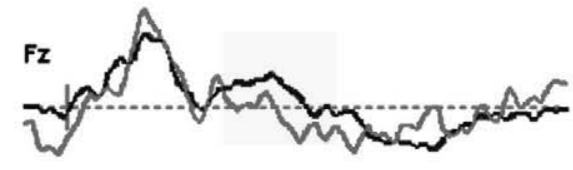

Controls

Incorrect Responses
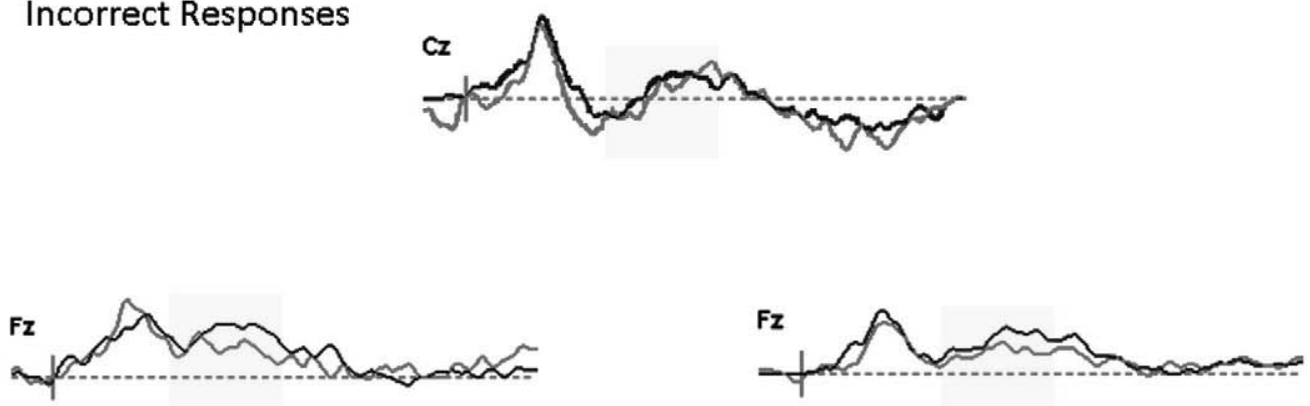

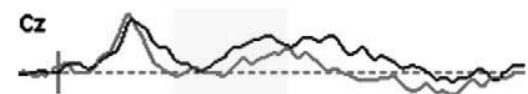

Easy Incorrect

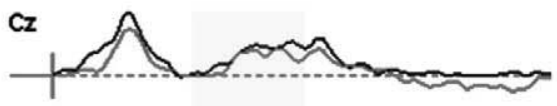

Difficult Incorrect

Fig. 1. ERP waveforms for the controls (blue) and at-risk (red) groups at electrodes $\mathrm{Fz}$ and $\mathrm{Cz}$ on a) correct and b) incorrect responses. 
Bonferroni-corrected t-tests further investigated significant main and interaction effects.

\section{Results}

\subsection{Demographic comparisons}

No significant differences were found between the at-risk and control groups on demographic factors such as age, sex, or handedness.

\subsection{Behavioural results}

A $2 \times 2$ mixed factorial ANOVA was performed with Task Difficulty (Easy, Difficult) as the within subjects variable and Group (Controls, At-Risk) as the between subjects variable. A main effect of Task Difficulty $[F(1,35)=555.569, \mathrm{p}=.000]$ illustrated higher accuracy scores for the Easy level compared to the Difficult level and an interaction effect of Task Difficulty*Group $[\mathrm{F}(1,35)=4.520, \mathrm{p}=.041]$ was also found. An independent t-test revealed a significant group difference on the Difficult level [ $\mathrm{t}(35)=2.249, \mathrm{p}=.031$ ]. This result illustrated higher accuracy scores for the controls compared to the at-risk group. The groups were compared on reaction time (RT) with a $2 \times 2$ ANOVA which yielded a main effect of Task Difficulty $[\mathrm{F}(1,35)=$ 20.803, $\mathrm{p}=.000]$. An independent t-test revealed a significant increase in RT on the Difficult level [t $(36)=-4.448, \mathrm{p}=.000$ ] compared to the Easy level. No significant group differences were found on reaction times.

\subsection{P300 mean amplitude and latency}

\subsubsection{Overall analyses}

A $2 \times 2$ repeated measures ANOVA was conducted to compare the P300 amplitude and latency across Task Difficulty (Easy, Difficult) and Electrode Site $(\mathrm{Fz}, \mathrm{Cz})$, regardless of accuracy scores. A main effect of Electrode Site $[\mathrm{F}(1,36)=6.610, \mathrm{p}=.014]$ and an interaction effect of Task Difficulty*Electrode Site $[\mathrm{F}(1,36)=5.371, \mathrm{p}=.026]$ were revealed. Paired t-tests demonstrated larger P300 amplitude at Fz than at $\mathrm{Cz}$ on the Easy level [ $\mathrm{t}(36)=3.202, \mathrm{p}=.003$ ]. There were no differences in P300 amplitude or latency across Task Difficulty. The P300 amplitude and latency was also compared across Condition (Correct, Incorrect) and Electrode Site (Fz, Cz), regardless of the level of difficulty. A significant interaction effect of Condition*Electrode Site $[F(1,36)=9.707, p=.004]$ was found. Paired t-tests revealed a significant difference between correct and incorrect responses at electrode $\mathrm{Cz}[\mathrm{t}(36)=2.218, \mathrm{p}=.033$ ]. However following Bonferroni correction for multiple paired t-tests, this significant effect was no longer maintained. No significant differences were found for P300 latency.

\subsubsection{Group analyses}

A $2 \times 2 \times 2 \times 2$ mixed factorial ANOVA compared the groups (Controls, At-Risk) on P300 amplitude across Condition (Correct, Incorrect), Task Difficulty (Easy, Difficult) and Electrode Site (Fz, Cz). The results yielded a significant Condition*Electrode Site* Group [F (1, $35)=5.233, \mathrm{p}=.028]$ interaction effect. A $2 \times 2 \times 2$ mixed factorial ANOVA compared the groups on the Easy and Difficult levels for correct responses only. The results revealed an interaction effect of Electrode Site*Group $[\mathrm{F}(1,35)=7.467, \mathrm{p}=.010]$. A $2 \times 2$ ANOVA on correct responses demonstrated a main effect of Group at electrode $\mathrm{Fz}[\mathrm{F}(1,35)=5.940, \mathrm{p}=.020]$. An independent t-test confirmed the group difference on correct responses for the Difficult level [t (35) = $2.168, \mathrm{p}=.037$ ], illustrating larger P300 amplitude in the controls compared to the at-risk group (see Fig. 2). The analyses were repeated for incorrect responses and no group differences were found. P300 latency was also examined but revealed no significant differences across Condition, Task Difficulty, Electrode Site or Group.

\section{Discussion}

This study investigated electrophysiological correlates of receptive language in adolescents reporting psychotic-like experiences compared to a control group. Overall, accuracy was decreased and reaction time was increased on the Difficult level of the task compared with the Easy level. The At-Risk group were characterised by decreased accuracy on the Difficult level compared to the controls but no group differences were found for reaction time. This finding supports previous behavioural reports of impaired receptive language in adolescents reporting PLEs (Cannon et al., 2002; Blanchard et al., 2010). The results of the behavioural analyses suggest that receptive language impairments are apparent in adolescents with PLEs.

On electrophysiological measures, the At-Risk group exhibited smaller P300 amplitude to correct responses in the Difficult level compared to the control group. According to Connolly et al. (2000), a diminished P300 to a correct response, in the context of language comprehension, reflects a failure to understand the meaning of the word. On an auditory oddball paradigm, decreased P300 is thought to reflect impaired updating of the context in working memory and the allocation of attentional processes (Donchin and Coles, 1988; Duncan et al., 2009; Polich and Donchin, 1988). However, these processes may also contribute to deficits in the comprehension of spoken language, such that processing new incoming stimuli (i.e. speech) may be impaired as a result of an inability to update the current context in working memory. Furthermore, evidence of a relationship between the P300 and language processing lies in the generators of the auditory P300, some of which reside in the left temporal lobe. McCarley et al. (1993) documented a relationship between reduced P300 amplitude in first-episode and chronic patients with schizophrenia and grey matter volume in the left superior temporal gyrus (STG). Wernicke's area is located in the superior temporal gyrus, which is an area responsible for the comprehension of spoken language. However, fMRI studies have also reported activation in the frontal cortex during receptive language tasks (Demonet et al., 1992; Bottini et al., 1994; Price et al., 1996).

P300 amplitude on the Difficult level was compared to the Easy level to ascertain whether this component could distinguish between the levels regardless of accuracy scores. The lack of a significant difference between the levels may have resulted from the inclusion of correct responses in the Difficult level as participants still obtained a relatively high number of correct answers at this level of difficulty. Furthermore, when the P300 was analysed based on behavioural accuracy, rather than on level of difficulty, the amplitude was larger for correct responses compared to incorrect responses. However, despite this finding being no longer significant following Bonferroni correction, previous studies support this trend where P300 amplitude was significantly larger in response to correct answers compared to incorrect answers (Connolly et al., 1995; 1999).

P300 latency did not differ across Group, Condition or Task Difficulty. The lack of a significant difference in P300 latency across Easy and Difficult levels suggest that efficient categorisation of complex task stimuli from the Difficult level may not have been affected in either of the groups. While P300 latency is usually prolonged in patients with schizophrenia, de Wilde et al. (2008) found that latency in young patients with recent onset schizophrenia is not significantly different to controls. Frangou et al. (1997) reported that P300 latency is related to age and illness duration, such that slowed latency is more apparent with increasing age and illness duration. Therefore, an increase in P300 latency may index a disruption in the speed of stimulus classification resulting from illness-related factors (Duncan et al., 2009). 


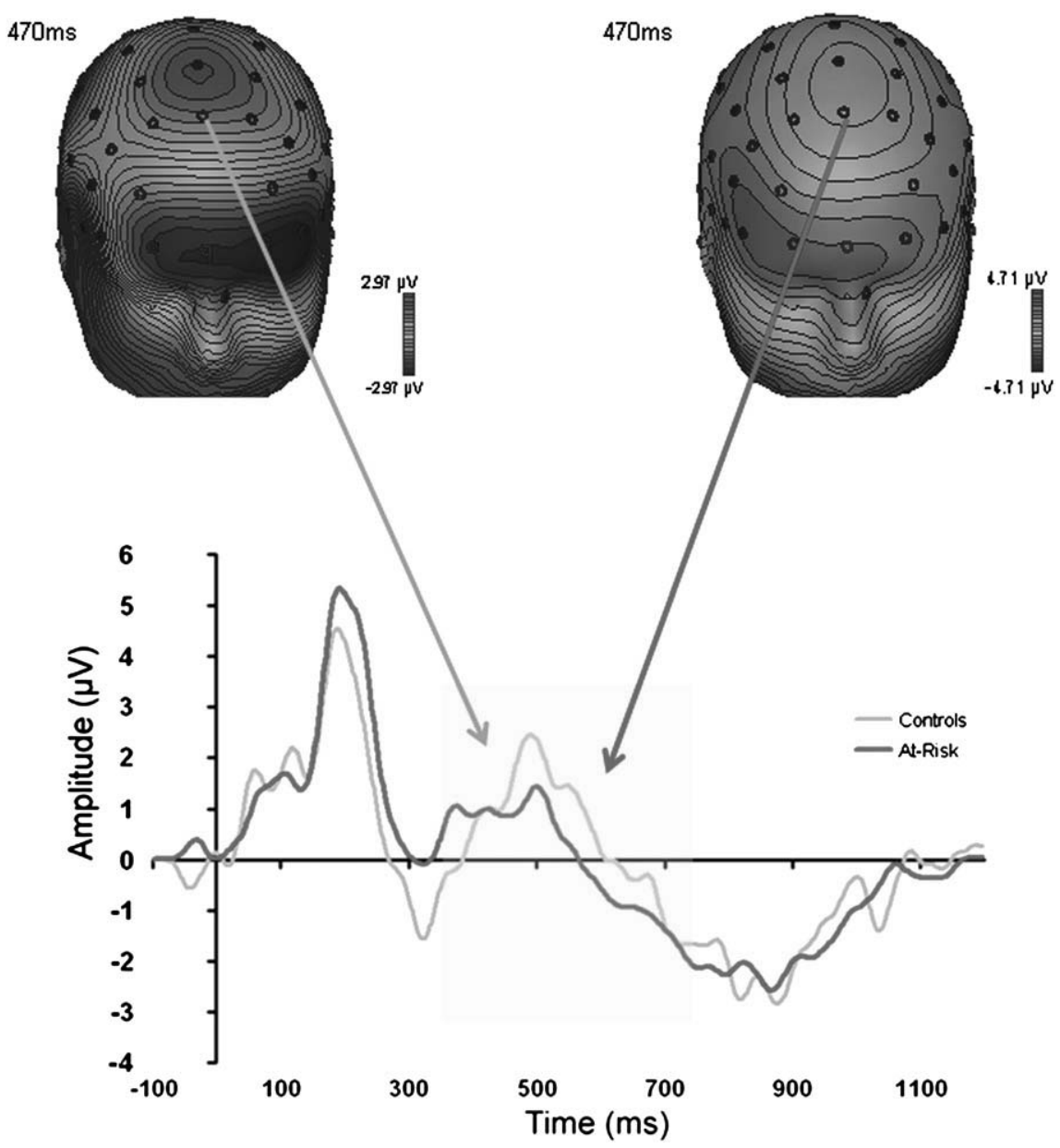

Fig. 2. The controls demonstrate larger P300 amplitude on correct responses on the difficult level compared to the at-risk group.

This study employed an established neuropsychological task while recording ERPs to investigate the neural correlates of receptive language in adolescents with PLEs in comparison to a group of controls. Evidence of a P300 to correct responses provides support for the identification of a potential ERP correlate of a complex cognitive function such as receptive language. Also, the use of a neuropsychological test facilitated the interpretation of the waveforms as the BPVS-II task is an established direct measure of receptive language. The results of this study lend support to previous evidence of a relationship between the P300 and the ability to understand spoken language. Furthermore, this is the first study to demonstrate neurophysiological correlates of disrupted receptive language processes in adolescents with psychotic symptoms.

A limitation of this study was the relatively small sample size and the lack of another comparison group with receptive language impairment. Comparing the P300 to another language impaired group may have provided further insight into the degree to which the P300 can index receptive language impairment. Further research investigating the P300 component in relation to receptive language may provide insight into the neural underpinnings of language deficits in those at-risk for schizophrenia. Follow-up studies of individuals at-risk for psychosis may elucidate whether receptive language deficits may confer increased risk for developing a psychotic disorder in adulthood. The results of this study demonstrate disrupted neural correlates of receptive language function in adolescents with PLEs, suggesting that the neurobiological mechanism underlying psychosis may be manifest in the adolescent period.

Supplementary materials related to this article can be found online at doi:10.1016/j.schres.2012.01.017.

\section{Role of funding source}

This work was supported by an Essel Foundation NARSAD Independent Investigator Award to MC. MC was supported by a Health Research Board (Ireland) Clinician Scientist Award. C.R. is supported by the Irish Research Council for Humanities and Socia Sciences (IRCHSS). F.K. was supported by an Alumni Undergraduate Summer Studentship from the Royal College of Surgeons in Ireland. The research leading to these results has also received funding from the European Community's Seventh Framework Programme under grant agreement No. HEALTH-F2-2010-241909 (Project EU-GEI). EUGEI is the acronym of the project 'European network of National Schizophrenia Networks Studying Gene-Environment Interactions'. The funding bodies had no further role in the study design, data collection, analysis and interpretation of the data; in the writing of the report and in the decision to submit the paper for publication.

\section{Contributors}

All authors recruited participants and their parents for the study. MB, MC and RR designed the study and MB and RR wrote the EEG protocol. Mathieu Blanchard, Ferga Kavanagh, Caroline Rawdon and Jennifer Murphy collected the data. Jennifer Murphy managed the literature searches and analyses, undertook the statistical analysis, and wrote the first and final draft of the manuscript. Dr. Roche compiled the graphics. All authors contributed to and have approved the final manuscript.

\section{Conflict of interest}

The authors report no conflict of interest.

\section{Acknowledgements}

We thank NUI Maynooth and the Clinical Research Centre Beaumont Hospital for the use of their facilities. We acknowledge the contribution of Derek Walsh, Paraic Scanlon and Jonathan Murphy (NUI Maynooth) for their technical assistance on data recording and analysis.

\section{References}

Berg, P., Scherg, M., 1991. Dipole models of eye movements and blinks. Electroencephalogr. Clin. Neurophysiol. 79 (1), 36-44. 
Blanchard, M.M., Jacobson, S., Clarke, M.C., Connor, D., Kelleher, I., Garavan, H., et al., 2010. Language, motor and speed of processing deficits in adolescents with subclinical psychotic symptoms. Schizophr. Res. 123 (1), 71-76.

Bottini, G., Corcoran, R., Sterzi, R., Paulesu, E., Schenone, P., Scarpa, P., et al., 1994. The role of the right hemisphere in the interpretation of figurative aspects of language. A positron emission tomography activation study. Brain 117, 1241-1253.

Bramon, E., Shaikh, M., Broome, M., Lappin, J., Berge, D., Day, F., et al., 2008. Abnormal P300 in people with high risk of developing psychosis. Neurolmage 41 (2) 553-560.

Byrne, J.M., Dywan, C.A., Connolly, J.F., 1995. An innovative method to assess the receptive vocabulary of children with cerebral palsy using event-related brain potentials. J. Clin. Exp. Neuropsychol. 17 (1), 9-19.

Cannon, M., Caspi, A., Moffitt, T.E., Harrington, H., Taylor, A., Murray, R.M., et al., 2002. Evidence for early-childhood, pan-developmental impairment specific to schizophreniform disorder: results from a longitudinal birth cohort. Arch. Gen. Psychiatry 59 (5), 449-456.

Condray, R., 2005. Language disorder in schizophrenia as a developmental learning disorder. Schizophr. Res. 73 (1), 5-20.

Condray, R., Steinhauer, S.R., van Kammen, D.P., Kasparek, A., 2002. The language system in schizophrenia: effects of capacity and linguistic structure. Schizophr. Bull. 28 (3), 475-490.

Connolly, J.F., D'Arcy, R.C., 2000. Innovations in neuropsychological assessment using event-related brain potentials. Int. J. Psychophysiol. 37 (1), 31-47.

Connolly, J.F., Byrne, J.M., Dywan, C.A., 1995. Event-related brain potentials reflect the receptive vocabulary of individuals as measured by the Peabody Picture Vocabulary Test - Revised: a study of cross-modal and cross-form priming. J. Clin. Exp. Neuropsychol. 17, 548-565.

Connolly, J.F., Major, A., Allen, S., D'Arcy, R.C., 1999. Performance on WISC-III and WAIS-R NI vocabulary subtests assessed with event-related brain potentials: an innovative method of assessment. J. Clin. Exp. Neuropsychol. 21 (4), 444-464.

Connolly, J.F., D'Arcy, R.C., Lynn Newman, R., Kemps, R., 2000. The application of cognitive event-related brain potentials (ERPs) in language-impaired individuals: review and case studies. Int. J.Psychophysiol. 38 (1), 55-70.

D'Arcy, R.C., Connolly, J.F., Eskes, G.A., 2000. Evaluation of reading comprehension with neuropsychological and event-related brain potential (ERP) methods. J. Int. Neuropsychol. Soc. 6 (5), 556-567.

de Wilde, O.M., Bour, L.J., Dingemans, P.M., Koelman, J.H., Boeree, T., Linszen, D.H. 2008. P300 deficits are present in young first-episode patients with schizophrenia and not in their healthy young siblings. Clin. Neurophysiol 119 (12), 2721-2726.

DeLisi, L.E., 2001. Speech disorder in schizophrenia: review of the literature and exploration of its relation to the uniquely human capacity for language. Schizophr. Bull. 27 (3), 481-496.

Demonet, J.-F., Chollet, F., Ramsay, S., Cardebat, D., Nespoulous, J.-L., Wise, R., et al., 1992. The anatomy of phonological and semantic processing in normal subjects. Brain 115, 1753-1768.

Donchin, E., Coles, M., 1988. Is the P300 component a manifestation of context updating? Commentary on Vereger's critique of the context updating model. Behav. Brain Science 11, 357-374.

Duncan, C.C., Barry, R.J., Connolly, J.F., Fischer, C., Michie, P.T., Naatanen, R., et al., 2009. Event-related potentials in clinical research: guidelines for eliciting, recording, and quantifying mismatch negativity, P300, and N400. Clin. Neurophysiol. 120 (11) 1883-1908.

Dunn, L., Whetton, C., Burley, J., 1997. British Picture Vocabulary Scale. nfer Nelson, London England.

Frangou, S., Sharma, T., Alarcon, G., Sigmudsson, T., Takei, N., Binnie, C., et al., 1997. The Maudsley Family Study, II: endogenous event-related potentials in familial schizophrenia. Schizophr. Res. 23 (1), 45-53.

Frommann, I., Brinkmeyer, J., Ruhrmann, S., Hack, E., Brockhaus-Dumke, A., Bechdolf, A., et al., 2008. Auditory P300 in individuals clinically at risk for psychosis. Int. J. Psychophysiol. 70 (3), 192-205.

Hanssen, M., Bak, M., Bijl, R., Vollebergh, W., van Os, J., 2005. The incidence and outcome of subclinical psychotic experiences in the general population. Br. J. Clin. Psychol. 44 (Pt 2), 181-191.

Henderson, L.M., Baseler, H.A., Clarke, P.J., Watson, S., Snowling, M.J., 2011. The N400 effect in children: relationships with comprehension, vocabulary and decoding. Brain Lang. 117 (2), 88-99.
Howlin, P., Mawhood, L., Rutter, M., 2000. Autism and developmental receptive language disorder-a follow-up comparison in early adult life. II: social, behavioural, and psychiatric outcomes. J. Child Psychol. Psychiatry 41 (5), 561-578.

Ille, N., Berg, P., Scherg, M., 2002. Artifact correction of the ongoing EEG using spatial filters based on artifact and brain signal topographies. J. Clin. Neurophysiol. 19 (2), 113-124.

Jeon, Y.W., Polich, J., 2003. Meta-analysis of P300 and schizophrenia: patients, paradigms, and practical implications. Psychophysiol. 40 (5), 684-701.

Kaufman, J., Birmaher, B., Brent, D., Rao, U., Ryan, N., 1996. The Schedule for Affective Disorders and Schizophrenia for School-aged Children: Present and Lifetime Version. University of Pittsburgh, Western Psychiatric Institute and Clinic.

Kelleher, I., Cannon, M., 2010. Psychotic-like experiences in the general population: characterizing a high-risk group for psychosis. Psychol. Med. 1-6.

Kelleher, I., Harley, M., Murtagh, A., Cannon, M., 2011. Are screening instruments valid for psychotic-like experiences? A validation study of screening questions for psychotic-like experiences using in-depth clinical interview. Schizophr. Bull. 37 (2), 362-369.

Klosterkotter, J., Hellmich, M., Steinmeyer, E.M., Schultze-Lutter, F., 2001. Diagnosing schizophrenia in the initial prodromal phase. Arch. Gen. Psychiatry 58 (2), 158-164.

Laurens, K.R., Hodgins, S., Maughan, B., Murray, R.M., Rutter, M.L., Taylor, E.A., 2007. Community screening for psychotic-like experiences and other putative antecedents of schizophrenia in children aged 9-12 years. Schizophr. Res. 90 (1-3), $130-146$.

Laurens, K.R., Hodgins, S., Mould, G.L., West, S.A., Schoenberg, P.L., Murray, R.M., et al., 2010. Error-related processing dysfunction in children aged 9 to 12 years presenting putative antecedents of schizophrenia. Biol. Psychiatry 67 (3), 238-245.

Mathalon, D.H., Ford, J.M., Rosenbloom, M., Pfefferbaum, A., 2000. P300 reduction and prolongation with illness duration in schizophrenia. Biol. Psychiatry 47 (5), 413-427.

McCarley, R.W., Shenton, M.E., O'Donnell, B.F., Faux, S.F., Kikinis, R., Nestor, P.G., et al., 1993. Auditory P300 abnormalities and left posterior superior temporal gyrus volume in schizophrenia. Arch. Gen. Psychiatry 50, 190-197.

McCarley, R.W., Salisbury, D.F., Hirayasu, Y., Yurgelun-Todd, D.A., Tohen, M., Zarate, C., et al., 2002. Association between smaller left posterior superior temporal gyrus volume on magnetic resonance imaging and smaller left temporal P300 amplitude in first-episode schizophrenia. Arch. Gen. Psychiatry 59 (4), 321-331.

O'Donnell, B.F., McCarley, R.W., Potts, G.F., Salisbury, D.F., Nestor, P.G., Hirayasu, Y., et al 1999. Identification of neural circuits underlying P300 abnormalities in schizophrenia. Psychophysiology 35, 388-398.

Ozgurdal, S., Gudlowski, Y., Witthaus, H., Kawohl, W., Uhl, I., Hauser, M., et al., 2008. Reduction of auditory event-related P300 amplitude in subjects with at-risk mental state for schizophrenia. Schizophr. Res. 105 (1-3), 272-278.

Polich, J., Donchin, E., 1988. P300 and the word frequency effect. Electroencephalogr. Clin. Neurophysiol. 70, 33-45.

Poulton, R., Caspi, A., Moffitt, T.E., Cannon, M., Murray, R., Harrington, H., 2000. Children's self-reported psychotic symptoms and adult schizophreniform disorder: a 15-year longitudinal study. Arch. Gen. Psychiatry 57 (11), 1053-1058.

Price, C.J., Wise, R.S.J., Frackowiak, R.S.J., 1996. Demonstrating the implicit processing of visually presented words and pseudowords. Cereb. Cortex. 6, 62-70.

Rajarethinam, R., Venkatesh, B.K., Peethala, R., Luan Phan, K., Keshavan, M., 2011. Reduced activation of superior temporal gyrus during auditory comprehension in young offspring of patients with schizophrenia. Schizophr. Res. 130,101-105.

Spironelli, C., Angrilli, A., Stegagno, L., 2008. Failure of language lateralization in schizophrenia patients: an ERP study on early linguistic components. J. Psychiatr. Neurosci. 33 (3), 235-243.

van Tricht, M.J., Nieman, D.H., Koelman, J.H., van der Meer, J.N., Bour, L.J., de Haan, L., et al. 2010. Reduced parietal $P 300$ amplitude is associated with an increased risk for a first psychotic episode. Biol. Psychiatry 68 (7), 642-648.

Wechsler, D., 1991. The Wechsler Intelligence Scale for Children-3, 3rd Edition. The Psychological Corporation, San Antonio, TX.

Welham, J., Scott, J., Williams, G., Najman, J., Bor, W. O'Callaghan, M., et al., 2009. Emotional and behavioural antecedents of young adults who screen positive for nonaffective psychosis: a 21-year birth cohort study. Psychol. Med. 39 (4), 625-634.

Winterer, G., Egan, M.F., Raedler, M., Sanchez, C., Jones, D.W., Coppola, R., et al., 2003. P300 and genetic risk for schizophrenia. Arch. Gen. Psychiatry 60, 1158-1167. 